Available online at http://jurnal.stmikroyal.ac.id/index.php/jurteksi

\title{
PERANCANGAN SISTEM INFORMASI PEMBUATAN KARTU TANDA MAHASISWA ONLINE DI STMIK ROYAL KISARAN
}

\author{
Irianto \\ Program Studi Sistem Informasi, STMIK Royal \\ email: irianto2121212@gmail.com
}

\begin{abstract}
Based on observations made in STMIK ROYAL Kisaran related to the manufacture of Student Identity Card, the campus is required to have a system that is really able to provide maximum service to students, because bothered in serving students for the process of making Student Identity Card, with this system will be expected students even more troublesome in making the application of Student Identity Card, which if initially students have to queue to fill out student data form next officer who input data and print and distributed to student, with student system enough to do data verification online which can be done anytime and anywhere then the operator will check through the website as admin then print the results of student data to be made Student ID Card.
\end{abstract}

Keywords: information system, student

\begin{abstract}
Abstrak: Berdasarkan pengamatan yang dilakukan di STMIK ROYAL Kisaran terkait pembuatan Kartu Tanda Mahasiswa, kampus dituntut memiliki sistem yang benar-benar mampu memberikan pelayanan yang maksimal terhadap mahasiswa, karena repotnya dalam melayani mahasiswa untuk proses pembuatan Kartu Tanda Mahasiswa, dengan adanya sistem ini nantinya diharapkan mahasiswa tidak repot lagi dalam membuat permohonan pembuatan Kartu Tanda Mahasiswa, yang mana jika awalnya mahasiswa harus antre untuk mengisi formulir data mahasiswa selanjutnya petugas yang menginput data dan mencetak dan di distribusikan ke mahasiswa, dengan sistem mahasiswa cukup melakukan verifikasi data secara online yang dapat dilakukan kapanpun dan dimanapun lalu operator akan cek melalui website sebagai admin selanjutnya mencetak hasil data mahasiswa untuk di jadikan Kartu Tanda Mahasiswa.
\end{abstract}

Kata kunci: sistem informasi, mahasiswa

\section{PENDAHULUAN}

Salah satu faktor pendukung perkembangan kampus adalah bagaimana membuat pelayanan terbaik, sehingga menjadi hal yang penting dalam membuat pelayanan digital dalam pembuatan kartu tanda mahasiswa, sehingga menghasilkan pelayanan yang sesuai dengan kebutuhan kampus. Seringkali dalam pembuatan kartu tanda mahasiswa menjadi hal yang sulit karena harus menemui petugas dan mengisi form yang disediakan.

Dalam pembuatan kartu tanda mahasiswa biasanya petugas kampus akan memberikan beberapa formulir 
Available online at http://jurnal.stmikroyal.ac.id/index.php/jurteksi

untuk diisi. Disini petugas akan melayani mahasiswa, memproses data hingga output pencetakan.

Untuk pembuatan kartu tanda mahasiswa yang akan dicetak, maka dibangun sebuah sistem pengambilan permohonan pencetakan terkomputerisasi yang mampu memudahkan proses pembuatan kartu tanda mahasiswa. perancangan sistem pembuatan kartu mahasiswa online di STMIK Royal kisaran. Intinya bahwa cara ini akan memudahkan mahasiswa dan petugas pembuatan kartu tanda mahasiswa dalam proses pembuatannya.

Sesuai dengan latar belakang masalah di atas maka dijabarkan beberapa rumusan masalah yaitu (1) Bagaimana merancang sistem untuk pelayanan online dalam membuat kartu tanda mahasiswa? (2) Bagaimana menerapkan data dan program pembuatan kartu tanda mahasiswa di STMIK Royal yang diaplikasikan berbasis web?

Ruang lingkup pembahasan dalam penelitian ini adalah mengangkat pembahasan mengenai pembuatan kartu tanda mahasiswa di STMIK Royal Kisaran. Sistem ini dirancang menggunakan bahasa pemrograman PHP \& MySQL.

Dalam penelitian ini ada beberapa tujuan yang hendak dicapai antara lain (1) Untuk membuat rancangan aplikasi pembuatan kartu tanda mahasiswa berbasis web. (2) Agar dapat mempermudah STMIK Royal Kisaran dalam melakukan pembuatan kartu tanda mahasiswa. (3) Membandingkan sejauh mana efesiensi dan efektifitas sistem informasi yang dirancang dengan sistem yang sedang berjalan.

Hasil penelitian ini akan bermanfaat (1) Memberikan alternatif pembuatan kartu tanda mahasiswa kepada STMIK Royal Kisaran yang nantinya dapat digunakan untuk memudahkan pekerjaan dalam sistem pembuatan kartu tanda mahasiswa. (2) Dari alternatif sistem yang ada akan dapat membantu
STMIK Royal Kisaran dalam pembuatan kartu tanda mahasiswa.

Menurut Sutabri (2012:10) sistem adalah suatu sistem dapat diartikan sebagai suatu kumpulan atau himpunan dari unsur, komponen, atau variabel yang terorganisir, saling berinteraksi, saling tergantung satu sama lain, dan terpadu.

Definisi sistem menurut Kadir (2010:15) adalah sekelompok elemenelemen yang saling terintegrasi dengan maksud dan tujuan yang sama untuk melaksanakan sasaran yang telah ditentukan.

Dari beberapa pengertian diatas dapat disimpulan bahwa bahwa sistem merupakan bekerjasamanya banyak unsur yang berada dalam suatu tempat untuk mendapatkan sesuatu yang diharapakan.

Informasi adalah pesan (ucapan atau ekspresi) atau kumpulan pesan yang terdiri dari order sekuens dari simbol, atau makna yang dapat ditafsirkan dari pesan atau kumpulan pesan. Informasi dapat direkam atau ditransmisikan. Hal ini dapat dicatat sebagai tanda-tanda, atau sebagai sinyal berdasarkan gelombang. Informasi adalah jenis acara yang mempengaruhi suatu negara dari sistem dinamis. Para konsep memiliki banyak arti lain dalam konteks yang berbeda. Informasi bisa di katakan sebagai pengetahuan yang didapatkan dari pembelajaran, penga-laman, atau instruksi. Namun, istilah ini memiliki banyak arti bergantung pada konteksnya, dan secara umum ber-hubungan erat dengan konsep seperti arti, pengetahuan, negentropy, Persepsi, Stimulus, komunikasi, kebenaran, repre-sentasi, dan rangsangan mental.

Ada beberapa elemen yang membentuk sebuah sistem, yaitu : tujuan, masukan, proses, keluaran, batas, mekanisme pengendalian dan umpan balik serta lingkungan. Berikut penjelasan mengenai elemen-elemen yang membentuk sebuah sistem :

1. Tujuan 
Available online at http://jurnal.stmikroyal.ac.id/index.php/jurteksi

Setiap sistem memiliki tujuan (goal), entah hanya satu atau mungkin banyak. Tujuan inilah yang menjadi pemotivasi yang mengarahkan sistem. Tanpa tujuan, sistem menjadi tak terarah dan tak terkendali. Tentu saja, tujuan antara satu sistem dengan sistem yang lain berbeda.

2. Masukan

Masukan (input) sistem adalah segala sesuatu yang masuk ke dalam sistem dan selanjutnya menjadi bahan yang diproses. Masukan dapat berupa halhal yang berwujud (tampak secara fisik) maupun yang tidak tampak. Contoh masukan yang berwujud adalah bahan mentah, sedangkan contoh yang tidak berwujud adalah informasi (misalnya permintaan jasa pelanggan).

3. Proses

Proses merupakan bagian yang melakukan perubahan atau transformasi dari masukan menjadi keluaran yang berguna dan lebih bernilai, misalnya berupa informasi dan produk, tetapi juga bisa berupa hal-hal yang tidak berguna, misalnya saja sisa pembuangan atau limbah. Pada pabrik kimia, proses dapat berupa bahan mentah. Pada rumah sakit, proses dapat berupa aktivitas pembedahan pasien.

4. Keluaran

Keluaran (output) merupakan hasil dari pemrosesan. Pada sistem informasi, keluaran bisa berupa suatu informasi, saran, cetakan laporan, dan sebagainya.

\section{Batas}

Yang disebut batas (boundary) sistem adalah pemisah antara sistem dan daerah di luar sistem (lingkungan). Batas sistem menentukan konfigurasi, ruang lingkup, atau kemampuan sistem. Sebagai contoh, tim sepak bola mempunyai aturan permainan dan keterbatasan kemampuan pemain. Pertumbuhan sebuah toko kelontong dipengaruhi oleh pembelian pelanggan, gerakan pesaing dan keterbatasan dana dari bank. Tentu saja batas sebuah sistem dapat dikurangi atau dimodifikasi sehingga akan mengubah perilaku sistem. Sebagai contoh, dengan menjual saham ke publik, sebuah perusahaan dapat mengurangi keterbatasan dana.

6. Mekanisme Pengendalian dan Umpan Balik

Mekanisme pengendalian (control mechanism) diwujudkan dengan menggunakan umpan balik (feedback), yang mencuplik keluaran. Umpan balik ini digunakan untuk mengendalikan baik masukan maupun proses. Tujuannya adalah untuk mengatur agar sistem berjalan sesuai dengan tujuan.

7. Lingkungan

Lingkungan adalah segala sesuatu yang berada di luar sistem. Lingkungan bisa berpengaruh terhadap operasi sistem dalam arti bisa merugikan atau menguntungkan sistem itu sendiri. Lingkungan yang merugikan tentu saja harus ditahan dan dikendalikan supaya tidak mengganggu kelangsungan operasi sistem, sedangkan yang menguntungkan tetap harus terus dijaga, karena akan memacu terhadap kelangsungan hidup sistem.

\section{METODOLOGI}

\section{Kerangka Kerja Penelitian (Frame Work)}

Kerangaka kerja ini merupakan langkah-langkah yang akan dilakukan dalam rangka penyelesaian masalah yang akan dibahas sehingga sasaran akhir dari penelitian yaitu hasil penerimaan pegawai dengan cepat, tepat, dan akurat dapat tercapai dan siap untuk diimplementasikan.

\section{Uraian Kerja}

Tahap ini menjelaskan tujuan yang akan dicapai dalam penelitian ini. Pada tujuan ini target yang akan dicapai, terutama yang dapat mengatasi permasalahan yang ada pada sistem pembuatan Kartu Tanda Mahasiswa 
Available online at http://jurnal.stmikroyal.ac.id/index.php/jurteksi

online di kampus STMIK Royal Kisaran.

\section{Mempelajari Literatur}

Pada tahap ini mencari literatur yang berhubungan dengan pemberian SPK, beasiswa, metode yang digunakan untuk perhitungan variabel. Mengikuti arahan dan petunjuk berdasarkan literatur yang ada dan yang berkaitan.

\section{Mengumpulkan Data}

Dalam hal ini data yang berkaitan dengan pembuatan Kartu Tanda Mahasiswa online di kampus STMIK ROYAL Kisaran akan dikumpulkan dan dicek berdasarkan rekapitulasi tahun tahun sebelumnya yang di backup petugas admin kampus.

\section{Analisis Sistem}

Metode analisa sistem yang digunakan adalah metode Deskriptif. Pada metode ini data yang ada dikumpulkan, disusun, dikelompokkan, dianalisa sehingga diperoleh beberapa gambaran yang jelas pada masalah penelitian tersebut.

\section{Perancangan Sistem}

Berikut ini tahapan dalam perancangan yang peneliti lakukan adalah: (1) Mempelajari literatur, (2) Membaca berbagai sumber terkait dengan permasalahan yang akan ditemukan solusinya, (3) Pembuatan Model Sistem, (4) Pembuatan pemodelan dalam conteks diagram agar lebih mudah dalam tahapan implementasi.

\section{Implementasi Sistem}

Implementasi sistem merupakan prosedur yang dilakukan untuk menyelesaikan desain sistem yang ada dalam dokumen desain yang disetujui, menguji sistem, menginstal, dan memulai sistem yang baru yang telah diperbaiki.

\section{Perangkat Lunak Yang Digunakan Xampp}

XAMPP menurut Bunafit Nugroho dalam bukunya "Pemrograman Web" (2014:1): menjelaskan bahwa "Saat ini telah banyak pilihan paket $P H P$ dan $M y S Q L$ yang dapat kita gunakan, salah satu yang paling populer adalah XAMPP. Paket lain, ada yang namanya AppServ, Apache2Triad dan paket yang lainnya. Dengan menginstal paket XAMMP, maka sekali instal kita sudah mendapatkan program $P H P, M y S Q L$ dan Apache. Dimana PHP untuk bahasa pemrogramannya, $M y S Q L$ untuk penyimpanan datanya atau databasenya, dan Apache untuk web server atau mesin yang berfungsi menjalankan skrip PHP di sisi server lokal". Anda dapat menggunakan paket XAMPP versi 1.7 dan juga versi 1.8 , keduanya dapat mendukung program yang dibahas.

\section{PHP \\ PHP (Hypertext Preprocessor) yang} digunakan sebagai bahasa siscript serverside dalam pengembangan web yang disisipkan pada dokumen $H T M L$. Penggunaan PHP memungkinkan web dapat dibuat dinamis sehinnga maintenance situs web tersebut menjadi lebih mudah dan efisien, (Beny Indra Murphy, 2010) dalam jurnal "Sistem Informasi". PHP merupakan software open-source yang disebarkan dan dilisesnsikan secara gratis serta dapat didownload sacara bebas dari situs resminya $h t t p: / / w w w . p h p . n e t$.

MySQL

MySQL menurut Bunafit Nugroho dalam bukunya "Pemrograman web" (2014:31) : menjelaskan bahwa "MySQL adalah software atau aplikasi database, yaitu software yang dapat kita pakai untuk menyimpan data berupa informasi teks dan juga angka. Semua informasi data yang dipakai di dalamsatu program aplikasi tersebut disimpan dalam satu Software Database, yaitu database $M y S Q L$. 
Available online at http://jurnal.stmikroyal.ac.id/index.php/jurteksi

Web Browser

Web Browser merupakan software yang berfungsi untuk menampilkan web di internet, web Browser sangat penting karena tanpa web browser kita tidak dapat membuka halaman website internet. Web browser yang digunakan harus mendukung software yang digunakan dalam mendesain web, yang tergolong kedalam web browser, seperti internet explorer, mozila firefox, opera, google crome, dan lain-lain.

\section{HASIL DAN PEMBAHASAN}

Analisis sistem berjalan merupakan gambaran tentang sistem yang diteliti dan diamati dari sistem yang saat ini masih dijalankan. Untuk dapat mengetahui kelebihan dan kekurangan dari sistem yang sedang berjalan saat ini, maka harus dilakukan analisis sistem sehingga dapat diketahui kelebihan dan kekurangan sistem yang nantinya dapat dikembangkan dan diperbaiki kedalam sistem yang baru. Tujuan dari sistem yang sedang berjalan ini adalah untuk mengetahui secara lebih terperinci seluruh kelemahan sistem yang lama sehingga dapat dengan mudah merancang sistem yang baru dengan perubahan yang lebih baik dibanding sistem yang lama.

Kelayakan sistem merupakan proses mempelajari dan menganalisa permasalahan yang telah ditentukan sesuai dengan tujuan akhir yang ingin dicapai, yang bertujuan untuk menguji apakah sistem baru yang akan diterapkan layak dipakai atau tidak. Adapun beberapa kelayakan sistem antara lain:

- Kelayakan teknik

Sistem secara kelayakan teknik dapat dilihat dari aspek teknologi yang dibangun menggunakan teknologi yang sudah ada dan mudah didapat serta mudah untuk dioperasikan.

- Kelayakan operasi

Sistem yang dibangun membantu pengguna dalam menyampaikan informasi yang dihasilkan dan membantu dalam mengorganisasikan informasi yang dibutuhkan pada saat yang tepat.

- Kelayakan ekonomi

Kelayakan ekonomi merupakan aspek yang paling domain. Dalam analisis kelayakan ekonomi diperlukan dua komponen, yaitu biaya dan manfaat. Apabila dilihat dari nilai manfaatnya yang lebih besar dari nilai yang dikeluarkan, tingkat efisien tinggi dan efektivitas maksimal, maka sistem yang akan dikembangkan bisa diterapkan.

\section{Permasalahan yang Dihadapi}

Adapun permasalahan yang dihadapi dalam penelitian ini bagaimana agar mahasiswa tidak antri pada saat pengisian berkas.

\section{Alternatif Pemecahan Masalah}

Adapun alternatif pemecahan masalah dalam aplikasi sistem pembuatan kartu tanda mahasiswa ini bagaiman siswa dapat mengajukan permohonan dipamanapun dan kapanpun.

\section{Perancangan Sistem}

Dalam pembuatan sebuah sistem perlu dilakukan perancangan tentang sistem yang akan dibuat. Hal ini dilakukan sebagai pedoman dalam pembuatan sistem baru. Pada aplikasi sistem pakar ini juga memerlukan suatu perancangan yang mana akan menggunakan pengetahuan atau fakta yang dikenal dengan basis pengetahuan serta perancangan program.

\section{Pengumpulan Data Mahasiswa}

Langkah awal pada sistem ini adalah bagaiamana mengumpulan data yang awalnya menggunakan data manual yang akan di pakai untuk proses pembuatan kartu tanda mahasiswa adapun data sebagai berikut:

- Aliran Sistem Informasi yang Sedang Berjalan 
Available online at http://jurnal.stmikroyal.ac.id/index.php/jurteksi

- Mahasiswa mengupul data ke admin

- Admin rekap

- Setelah rekap lanjut ke pencatakan

- Admin memberi ke ketua untuk di tandatangani

- Admin distribusi KTM ke mahasiswa

Tabel 1 Tabel Form Pengisian Data Diri Mahasiswa

\begin{tabular}{|c|c|c|}
\hline No & Masukkan & Keterangan \\
\hline 1 & NIM & $\begin{array}{l}\text { Berisi Angka } \\
\text { yang terdiri dari } 8 \\
\text { Digit }\end{array}$ \\
\hline 2 & $\begin{array}{l}\text { Nama } \\
\text { Lengkap }\end{array}$ & Berisi teks \\
\hline 3 & $\begin{array}{l}\text { Tempat } \\
\text { Lahir }\end{array}$ & Berisi teks \\
\hline 4 & $\begin{array}{l}\text { Tanggal } \\
\text { Lahir }\end{array}$ & Berisi Nomor \\
\hline 5 & Alamat & $\begin{array}{l}\text { Berisi Teks dan } \\
\text { Nomor }\end{array}$ \\
\hline 6 & Jenjang & Berisi Teks \\
\hline 7 & $\begin{array}{l}\text { Program } \\
\text { Studi }\end{array}$ & Berisi Teks \\
\hline 8 & Kelas & $\begin{array}{l}\text { Berisi teks dan } \\
\text { nomor }\end{array}$ \\
\hline 10 & $\begin{array}{l}\text { Foto } \\
\text { Berwarna }\end{array}$ & $\begin{array}{l}\text { Memakai } \\
\text { Almamater } \\
\text { ukuran max } 1 \mathrm{Mb}\end{array}$ \\
\hline
\end{tabular}

\section{Hasil}

Dalam pembuatan aplikasi ini, perangkat lunak dan bahasa pemrograman yang digunakan peneliti adalah bahasa Sublime text serta database PHP Mysql untuk menampilkan implementasi aplikasi pada komputer dalam implementasi visual yang akan ditampilkan.

\section{Tampilan Utama}

Pada gambar dibawah ini menampilkan halaman Depan dan Login, untuk masuk sebagai admin.

\section{Tampilan Login}

Gambar dibawah ini admin dapat login untuk menjalankan program, menu ini dapat di gunakan oleh user ataupun admin.

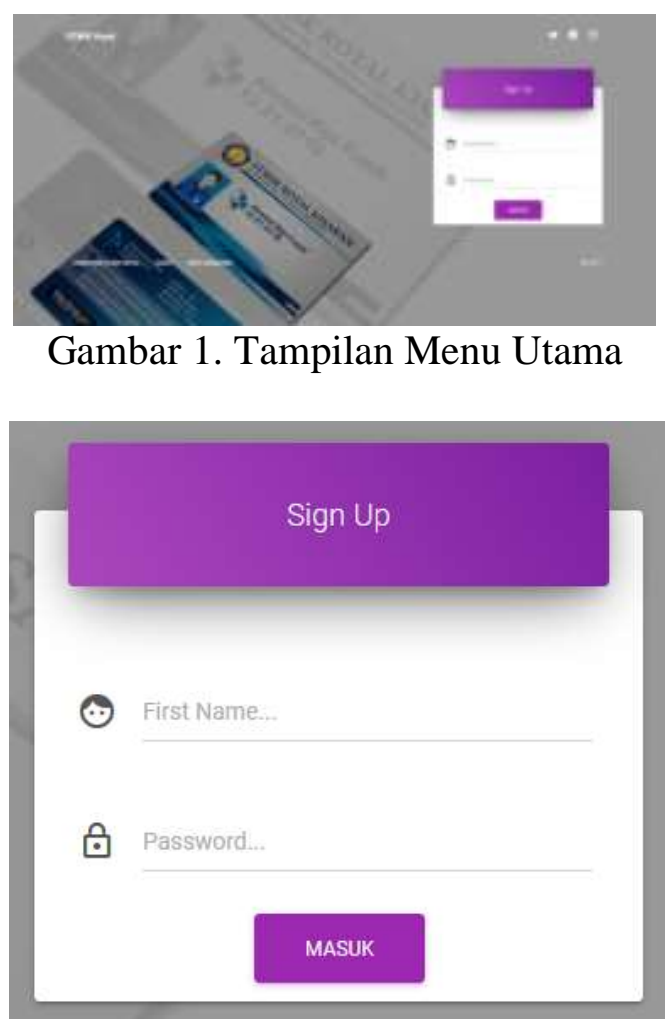

Gambar 2. Tampilan Menu Input Login

\section{Tampilan login admin}

Pada gambar 3 menampilkan menu yang akan di jalankan oleh admin yang dapat dilakukan pengecekan mahasiswa yang sudah mendaftar sampai dengan cetak.

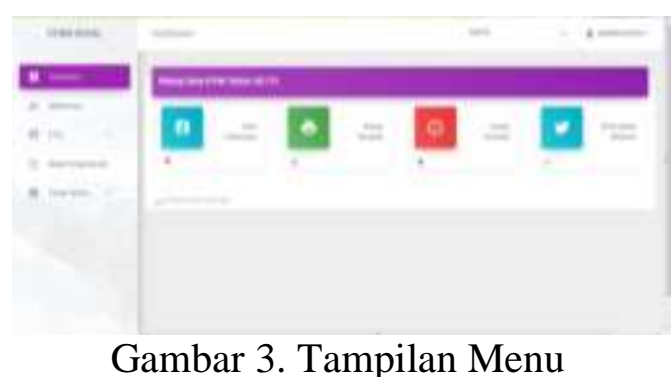

Gambar 3. Tampilan Menu

\section{Keseluruhan Setelah Login Admin}

Tampilan Data Mahasiswa

Sudah Tercetak. Pada gambar 4 
Available online at http://jurnal.stmikroyal.ac.id/index.php/jurteksi

menunjukan nama mahasiswa yang sudah tercetak maupun yang belum

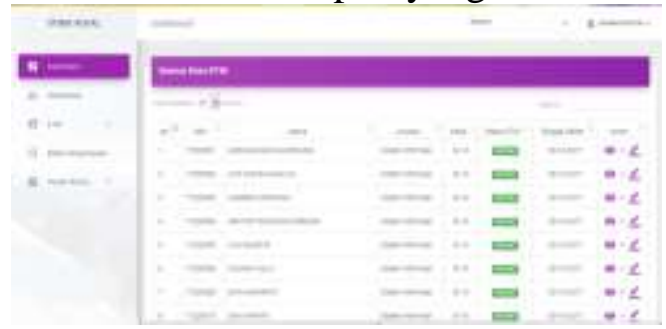

Gambar 4. Tampilan Data Mahasiswa Sudah Tercetak

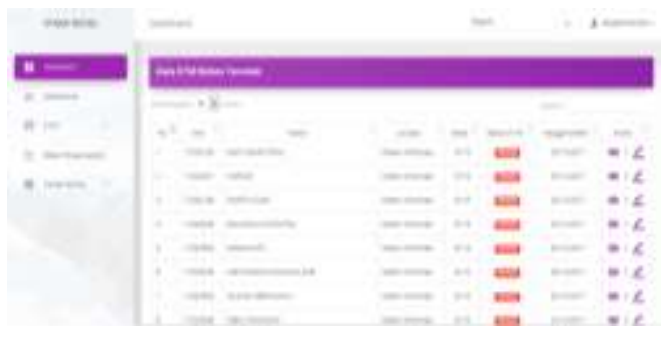

Gambar 5. Tampilan Data Mahasiswa Belum Tercetak

\section{Tampilan Login Mahasiswa}

Pada bagian ini Mahasiswa dapat memasukkan data diri untuk permohonan pengajuan kartu tanda 4. mahasiswa.

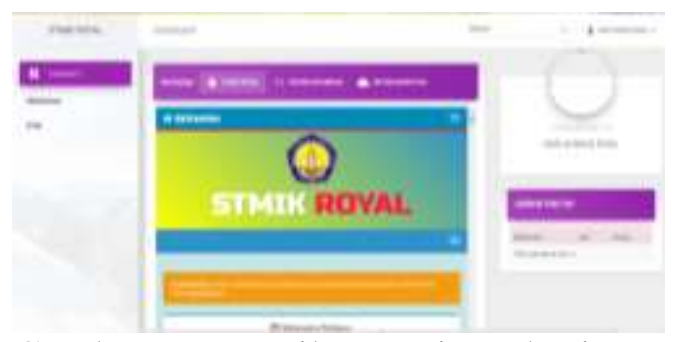

Gambar 6. Tampilan LoginMahasiswa

\section{Tampilan Data Mahasiswa}

Pada gambar 7 diperlihatkan untuk profil data diri mahasiswa.

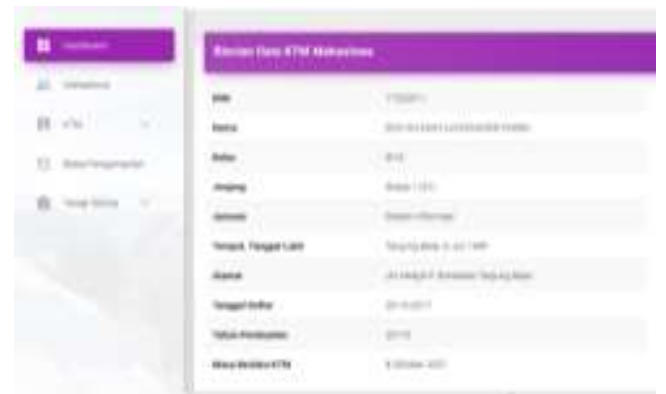

Gambar 7. Tampilan Data Diri Mahasiswa

\section{SIMPULAN}

Adapun simpulan yang didapat setelah melakukan penelitian ini adalah:

1. Aplikasi ini dapat digunakan untuk mempermudah pembuatan kartu tanda mahasiswa

2. Kelebihan aplikasi ini dapat di pakai secara online

3. Cara input data tidak terlalu rumit 


\section{DAFTAR PUSTAKA}

Alatas, H. 2015. Proyek Membangun Responsive Web Desain dengan Bootstrap 3 dan 4. Yogyakarta : Lokomedia

Sianipar, R.H. (2015). HTML 5 dan CSS3. Bandung: Informatika
Raharjo, B. (2015). Belajar Otodidak Framework Yii. Jakarta: Informatika

Wardana. (2014). Aplikasi Website Profesional dengan PHP dan JQUERY. Jakarta: Elex Media Komputindo 